\title{
Reflets
}

Revue ontaroise d'intervention sociale et communautaire

\section{Fiers de nos enfants : des maisons de la famille liées à une approche communautaire globale dans Prescott-Russell}

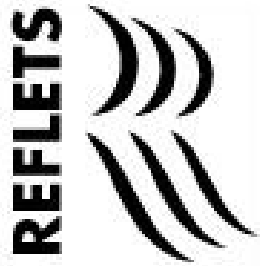

\section{Philippe Lelièvre}

Volume 3, numéro 1, printemps 1997

Enfance et familles en contexte d'appauvrissement

URI : https://id.erudit.org/iderudit/026160ar

DOI : https://doi.org/10.7202/026160ar

Aller au sommaire du numéro

Éditeur(s)

Reflets : Revue ontaroise d'intervention sociale et communautaire

ISSN

1203-4576 (imprimé)

1712-8498 (numérique)

Découvrir la revue

Citer cet article

Lelièvre, P. (1997). Fiers de nos enfants : des maisons de la famille liées à une approche communautaire globale dans Prescott-Russell. Reflets, 3(1), 158-161. https://doi.org/10.7202/026160ar

Tous droits réservés (C) Reflets : Revue ontaroise d'intervention sociale et communautaire, 1997
Ce document est protégé par la loi sur le droit d'auteur. L'utilisation des services d'Érudit (y compris la reproduction) est assujettie à sa politique d'utilisation que vous pouvez consulter en ligne.

https://apropos.erudit.org/fr/usagers/politique-dutilisation/ 


\title{
Fiers de nos enfants: des maisons de la famille liées à une approche communautaire globale dans Prescott-Russell
}

\author{
Philippe Lelièvre \\ Coordonnateur du programme Fiers de nos enfants de Prescott-Russell
}

En juin 1994, débutait l'implantation d'un projet PACE (Programme d'action communautaire pour les enfants) subventionné par le gouvernement fédéral (Santé et Bien-être social) dans la région de Prescott-Russell. Le projet Fiers de nos enfants est le fruit de plusieurs mois de réflexion et d'échanges entre parents, organismes communautaires et agences professionnelles.

Ayant pour but de rapprocher certaines ressources communautaires ainsi que l'ensemble des jeunes familles et des enfants (0-6 ans), ce projet émerge suite à la prise de conscience de plusieurs besoins et manques, mais surtout du potentiel et de la richesse des forces et des ressources qui ne demandent qu'à mieux jouer leur rôle. A l'échelle locale, une stricte vision de besoins peut s'avérer paralysante : que faire devant la pauvreté qui touche les familles d'un enfant sur cinq, l'éclatement des familles, l'effritement du tissu social, l'isolement, les listes d'attente des agences, les relations de dépendance?

Devant l'ampleur de la tâche, ce projet ne veut surtout pas s'attaquer à des manques mais plutôt participer à l'émancipation des ressources. Il veut favoriser la création de liens d'interdépendance entre parents ainsi qu'entre parents et ressources, 
liens qui constituent les conditions essentielles d'une véritable communauté. La mise en place de lieux d'interactions entre parents s'effectue avec l'ensemble des ressources professionnelles et communautaires. Ce lieu de créativité géré entièrement par les parents et surnommé Maison de la famille constitue la clef de voûte de notre approche communautaire globale.

Les familles ciblées, souvent marginalisées sur le plan économique, social, de l'éducation et géographique, et ayant des enfants de 0-6 ans, ne sont pas rejointes par un service spécialisé géré strictement par des professionnels, risquant de perpétuer des liens de dépendance. Ces familles sont attirées par un milieu environnant qui prend conscience des valeurs rattachées à la famille et aux enfants, aux ressources de celles-ci et qui se facilite les liens d'interdépendance et l'échange de talents et de ressources entre parents de différents milieux.

Pour réaliser cet idéal, les objectifs du projet se rattachent à 3 buts principaux :

- Dans une optique de marketing social, consolider une action communautaire concertée visant à favoriser un environnement favorable aux enfants de 0-6 ans et aux jeunes familles.

- Dans une optique de développement communautaire, favoriser la prise en charge des stratégies par les parents, le réseautage et le leadership des parents avec la participation des ressources professionnelles et communautaires.

- Dans une optique de développement des compétences parentales, accroître la capacité des parents et des aidants à favoriser le développement physique, émotif et intellectuel des enfants de 0-6 ans.

Ces trois buts sont interreliés pour la réalisation d'une véritable approche communautaire globale. Sur le plan du marketing social, les stratégies visent à promouvoir les valeurs rattachées à l'émancipation de la famille et au droit des enfants de se développer dans un environnement sain et accueillant.Afin de se donner une base commune de collaboration les parents et les ressources communautaires sont invitées à signer des déclarations de valeurs prônant la famille et les enfants. Les médias sont aussi des 
partenaires actifs pour créer un climat d'accueil au mouvement Fiers de nos enfants où chacun s'interroge sur la façon de s'investir davantage auprès de l'enfant et la famille.

Ce travail de sensibilisation communautaire s'effectuant, les parents peuvent plus facilement assumer leur leadership et mieux échanger leur talents et leurs ressources. Des projets communs confirment et appuient ces efforts : maisons de la famille, groupes de soutien, groupes de jeu, boîtes de jeux thématiques, ateliers. La maison de la famille constitue la clef de voûte de ces projets. Ouvertes à l'été et l'automne 1995, les quatre maisons de la famille de Prescott-Russell constituent un réseau rassembleur pour les parents. Suite à des assemblées publiques tenues dans les communautés concernées, des comités de parents ont été mis en place afin de choisir les lieux et planifier les programmations de ces maisons. Bien que différentes, parce que bâties à l'image de leurs communautés respectives, ces maisons de la famille remplissent toutefois des fonctions communes: socialisation et stimulation des jeunes enfants, dépistage, échanges entre parents, entraide, apprentissage, activités de lobbying pour la famille et les jeunes enfants. Pour réaliser ces fonctions, chaque maison est gérée par un comité de maison formé de parents où l'agente de développement et l'animatrice à temps partiel agissent comme personnes-ressources pour la concrétisation des projets des parents. Le comité de gestion du mouvement Fiers de nos enfants est formé principalement de parents élus pour représenter les maisons de la famille et de huit agences actives auprès de la famille et des enfants. Par sa composition, ce comité de gestion boucle un retour au volet marketing social.

Les deux volets de marketing social et de développement communautaire ont dominé les deux premières années du projet. Maintenant que les parents se regroupent et s'organisent le projet voit à faciliter l'acquisition des compétences parentales en favorisant l'échange de ressources et de talents entre parents, l'organisation de groupes de discussion, de groupes d'échanges, de répit et aussi en impliquant les agences actives dans le développement de compétences parentales. Cette collaboration permet aux agences de réseauter de façon plus efficace avec un 
regroupement de parents déjà existant. Pour les parents, le lien avec les agences permet d'influencer le contenu des services offerts en fonction de leurs besoins. L'accroissement des compétences parentales touche bien sûr la relation parent-enfant mais aussi l'acquisition de compétences de base telles que la confiance en soi et le leadership.

Par cette approche communautaire globale nous espérons que les adultes et les agences qui ont à coeur les enfants et la famille puissent mieux jouer leur rôle dans la communauté et que les parents soient mieux appuyés dans leur rôle de ressource et de multiplicateur auprès d'autres parents. 